Supplement of Ocean Sci., 15, 333-348, 2019

https://doi.org/10.5194/os-15-333-2019-supplement

(C) Author(s) 2019. This work is distributed under

the Creative Commons Attribution 4.0 License.

(c) (1)

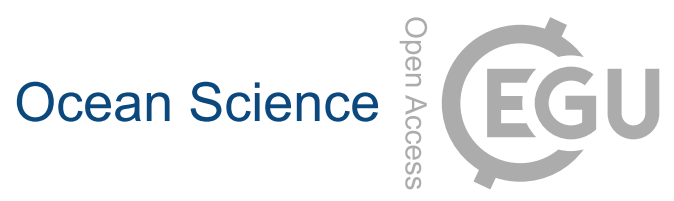

Supplement of

\title{
Seasonal and inter-annual variability of water column properties along the Rottnest continental shelf, south-west Australia
}

Miaoju Chen et al.

Correspondence to: Miaoju Chen (miaoju.chen@research.uwa.edu.au)

The copyright of individual parts of the supplement might differ from the CC BY 4.0 License. 


\section{Introduction}

The supporting information provides additional figures that include the mean seasonal cross-shelf transects of temperature (Figure S1); salinity (Figure S2); chlorophyll concentration (Figure S3); and density (Figure S4).

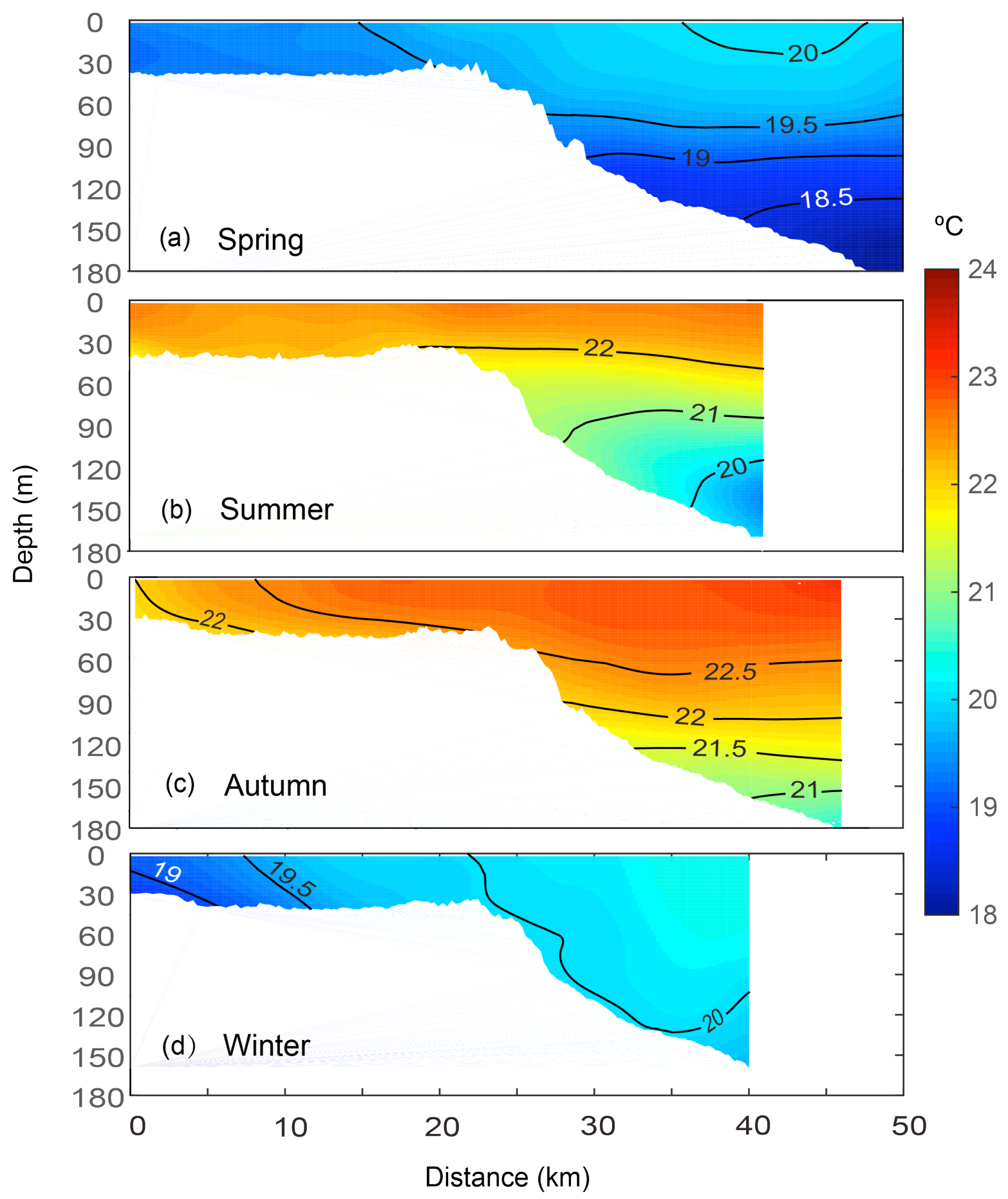

Figure S1: Mean vertical structure of temperature $\left({ }^{\circ} \mathrm{C}\right.$ ) for (a) spring, (b) summer, (c) autumn, (d) winter averaged seasonally over distance and depth across the Rottnest continental shelf between 2009 and 2015. 


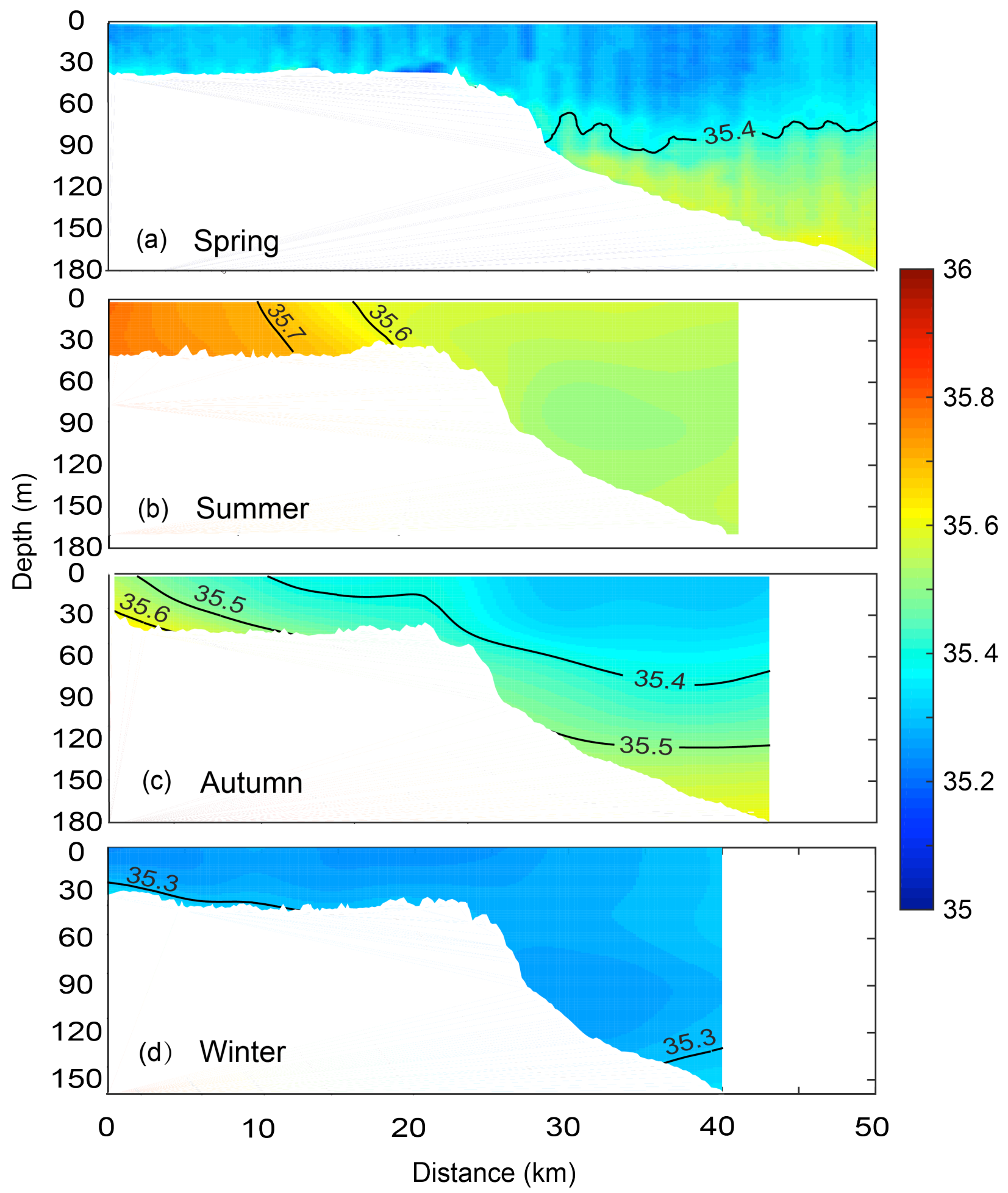

Figure S2: Mean vertical structure of salinity in each season for (a) spring, (b) summer, (c) autumn, (d) winter averaged seasonally over distance and depth across the Rottnest continental shelf between 2009 and 2015. 


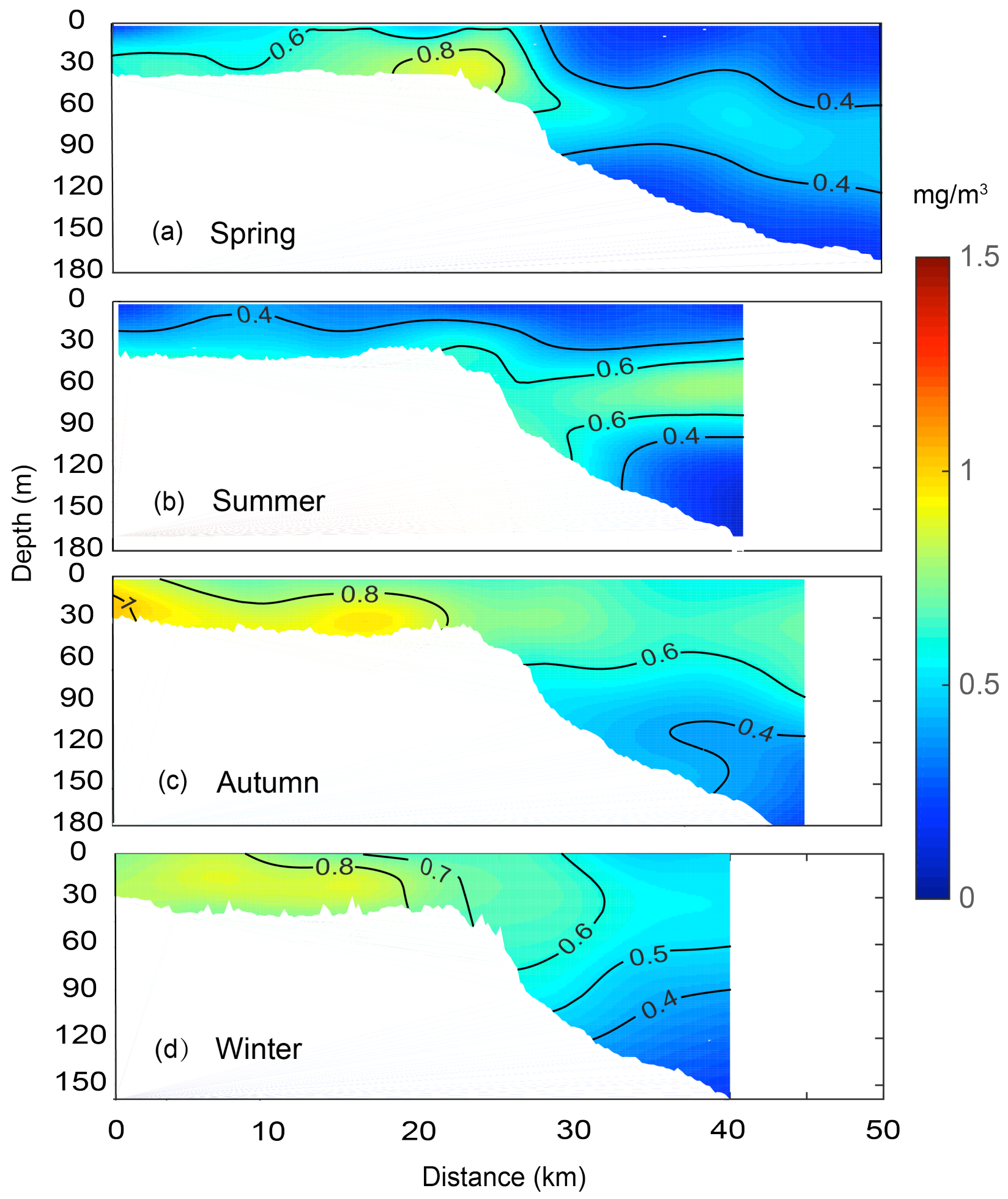

Figure S3: Mean vertical structure of fluorescence $\left(\mathrm{mg} / \mathrm{m}^{3}\right)$ in each season for (a) spring, (b) summer, (c) autumn, (d) winter averaged seasonally over distance and depth across the Rottnest continental shelf between 2009 and 2015. 


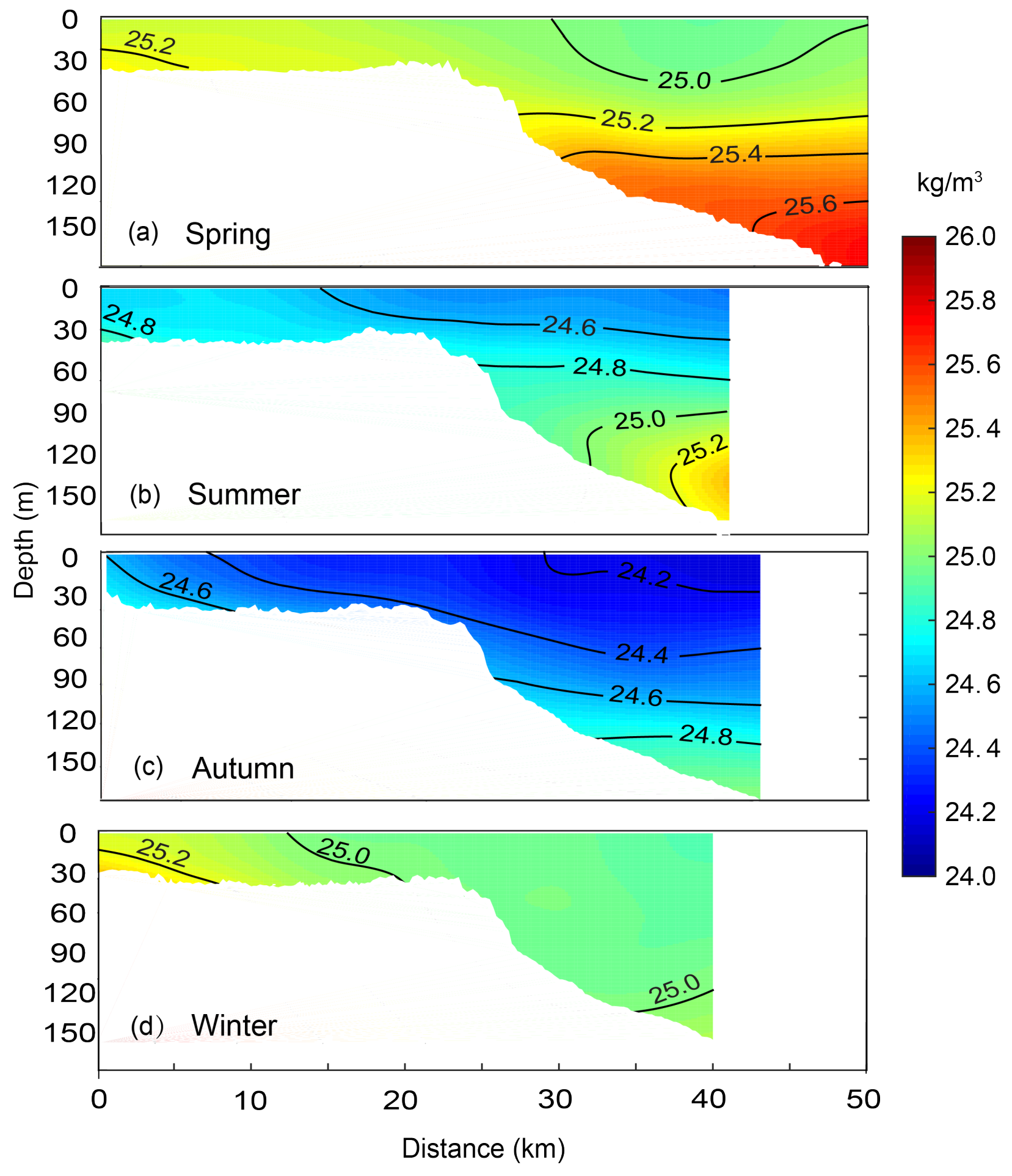

Figure S4: Mean vertical structure of density as sigma-t $\left(\mathrm{kg} / \mathrm{m}^{3}\right)$ for (a) spring, (b) summer, (c) autumn, (d) winter averaged seasonally over distance and depth across the Rottnest continental shelf between 2009 and 2015. 